Research Article

\title{
Childhood autism: knowledge and perception among university students in United Arab Emirates
}

\author{
Suleiman Ibrahim Sharif *, Laila M. T. Bughaigis, Manar Salah, \\ Noor Kariem, Arsha Mohamed
}

\author{
Department of Pharmacy \\ Practice and \\ Pharmacotherapeutics, College \\ of Pharmacy, University of \\ Sharjah - P. O. Box 27272- \\ United Arab Emirates
}

Received: 21 May 2016

Accepted: 01 July 2016

\section{*Correspondence to:}

Dr. Suleiman Ibrahim Sharif,

Email: sharifsi@sharjah.ac.ae

Copyright: (C) the author(s), publisher and licensee Medip Academy. This is an openaccess article distributed under the terms of the Creative Commons Attribution NonCommercial License, which permits unrestricted noncommercial use, distribution, and reproduction in any medium, provided the original work is properly cited.

\begin{abstract}
Background: Adequate knowledge and awareness about childhood autism allows early diagnosis and interventions. The present study was carried out to assess the knowledge and perception of university students about childhood autism.

Methods: A cross-sectional study was conducted to evaluate the level of knowledge and awareness about autism spectrum disorder among university students. A total of 400 students were randomly enrolled from five universities. The questionnaire covered the major aspects of autism.

Results: Only 300 questionnaires were fully completed giving a response rate of $75 \%$. The majority of respondents agreed that autism is a neurodevelopmental disorder with strong genetic basis where family history increases chances of developing autism. They believe that vaccination, poor parenting and environmental factors are not causes of autism. Large numbers of participants were not sure if autism is more common in males than females but agreed that early identification improves the therapeutic outcomes while $44 \%$ believed that children can outgrow autism with proper treatment. More than 50\% of respondents disagreed to the statements that autistic children are intellectually disabled and all display poor eye contact. Only $20 \%$ of students agreed that autistics children have mental disabilities, while about $50 \%$ believed that they can live independently.

Conclusions: University students seem to hold adequate knowledge about major hallmarks of the disorder. However, more efforts are needed to enhance awareness of not only parents and relatives but also the general public so that they can deal responsibly with identified cases of autistic children.
\end{abstract}

Keywords: Childhood autism, Knowledge, Perception, University students, United Arab Emirates

\section{INTRODUCTION}

Autism Spectrum Disorders (ASD) are pervasive and lifelong neuro-developmental disorders characterized by impaired socialization, impaired verbal and nonverbal communication, and restricted interests and repetitive patterns of behavior. ${ }^{1}$ Childhood autism is a pervasive developmental disorder with negative impact on the development of child's social, behavioural and communication skills. Knowledge and awareness about this condition differ from country to country being of a better level in developed than in developing countries. Adequate knowledge and awareness about childhood autism allows early diagnosis and interventions and greatly improve care and therapeutic outcomes. ${ }^{2,3}$ The prevalence of the ASD has progressively increased from 1 in 500 to 1 in $50 .^{4-6}$ Awareness has been suggested to be a reason among others that contributed to the increased prevalence of ASD. ${ }^{7}$ Various studies reported different levels of awareness. General population surveys in Northern Ireland reported that $82 \%$ of the public have heard of autism while in UK a $92 \%$ of the public exhibited awareness of autism. ${ }^{7,8}$ The high level of awareness in the first study has been claimed to be a reflection of the fact that nearly two thirds of the sample had a family member with autism or knew someone with 
autism in their wider social circle. ${ }^{7}$ The objective of this preliminary study was to assess the knowledge of childhood autism among university students in United Arab Emirates.

\section{METHODS}

The sample comprised 300 adults aged 18-28 years from various colleges in the University of Sharjah and other universities in UAE. The questionnaire was pre-piloted by distributing it to 10 students and their comments and recommendations were taken into consideration in the final version of the survey. The study was anonymous and identity of participants was disguised. Initially questionnaires were distributed to 400 students and 325 filled in questionnaires were received back with 25 surveys being incompletely filled and were thus rejected.

The descriptive, cross-sectional survey consisted of 30 closed-ended and multiple choice questions. The first part covered questions dealing with demographic characteristics of the participants including age, gender, having a family child or a relative with autism. Other questions dealt with views of participants on whether autism has strong genetic basis, autistic children are intellectually disabled, display poor eye contact. Also views on various assumed causes of autism such as vaccination, poor parenting, environmental factors and family history. Other questions covered hall marks of autism such as whether the disorder is lifelong one, autistics can live independently, autistics have mental disabilities and delay in early communication as an early symptom. In addition participants were asked whether autistics can overgrow the syndrome with proper treatment, whether they know of the availability of a medical diagnosing test for the disorder, is it more common in males than females and whether early detection can improve therapeutic outcomes. The data is presented as $\%$.

\section{RESULTS}

As we received back 325 filled in questionnaires of which 25 were incomplete and were rejected, the response rate was $75 \%$. Participants were all students from various colleges of various universities in United Arab Emirates (UAE) with age ranging from 18-28 years. The ratio of female to male participants was $3: 1$. Only $15(5 \%)$ of the respondents have autistic relative. About two thirds (195, $65 \%$ ) of respondents agreed or strongly agreed that autism is a neuro-developmental disorder with strong genetic basis (Figure 1). The majority $(64.6 \%$ and $42.2 \%)$ of participants were not sure if autism is more common in males than females and that there is no medical diagnostic test respectively. On the other hand, about 228 (76\%) students agreed that early identification improves the therapeutic outcomes while 132 (44\%) believed that children can outgrow autism with proper treatment (Figure 2). More than $50 \%$ of respondents disagreed or strongly disagreed to the statement that autistic children are intellectually disabled (Figure 3). Again the majority of respondents disagreed and strongly disagreed that all autistic children display poor eye contact (Figure 4). Only a few participants $(60,20 \%)$ agreed that autistics children have mental disabilities, while about $50 \%$ believed that they can live independently while $60 \%$ agreed that delay in early communication is an early sign of the disorder and about $52 \%$ believed that the disorder is a lifelong one (Figure 5.). The majority of participants $(207,69 \%)$ agreed that family history increases chances of developing autism while believing that vaccination, poor parenting and environmental factors are not causes of autism (Figure 6).



Figure 1: Responses of University students to the statement that autism is a neuro-developmental disorder with a strong genetic basis.

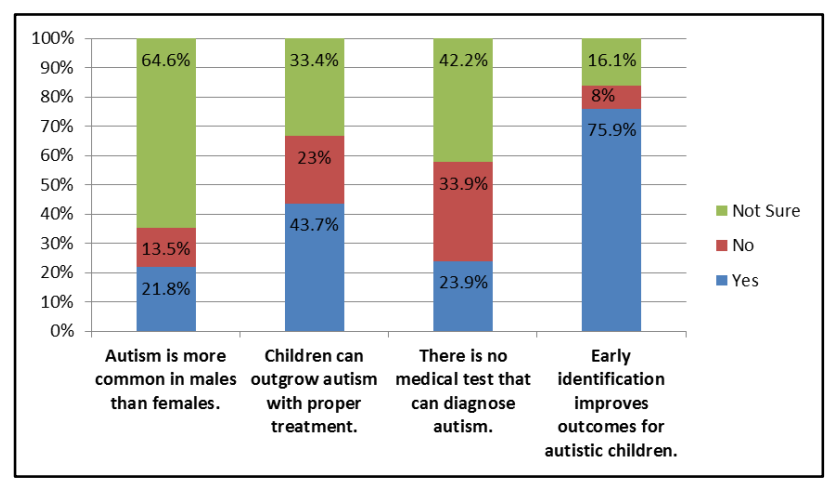

Figure 2: Responses of students to some aspects of autism.

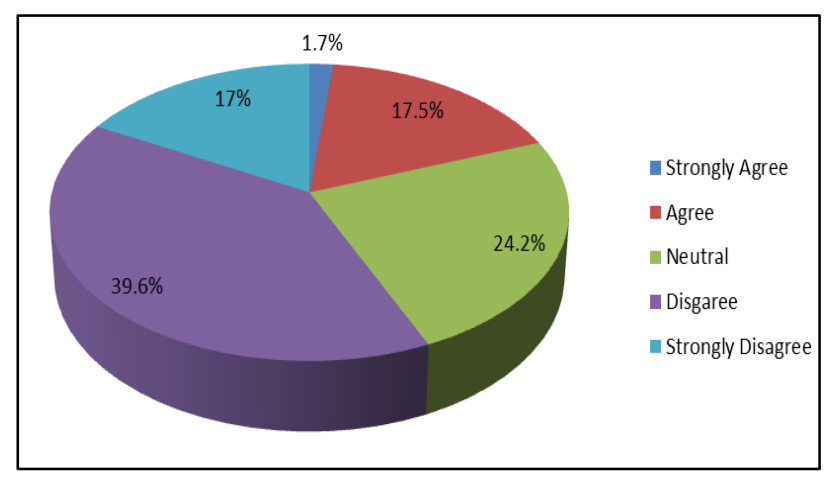

Figure 3: Responses of students to the statement that autistic children are intellectually disabled. 


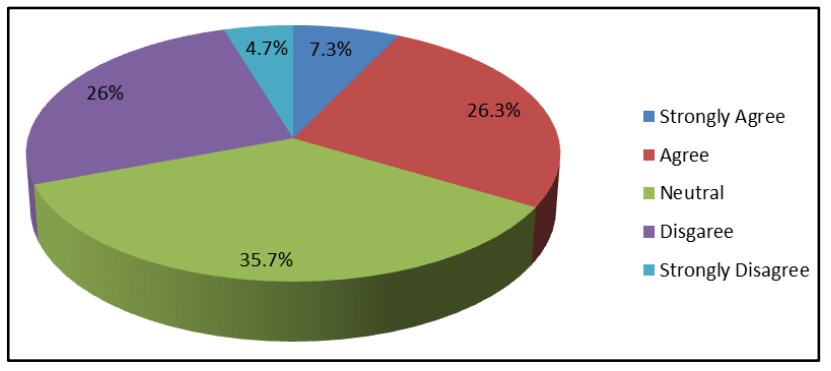

Figure 4: Responses of students to the statements that all autistic children have poor direct eye contact.

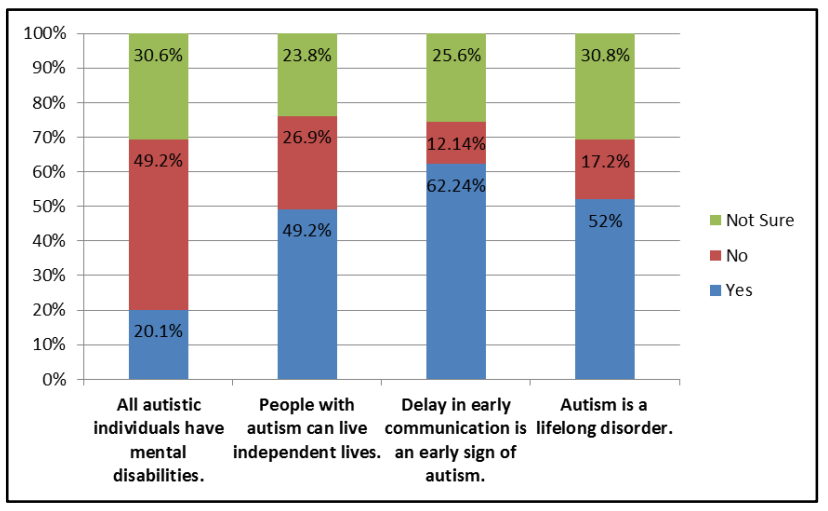

Figure 5: Responses of university students to suggested hallmarks of autism.

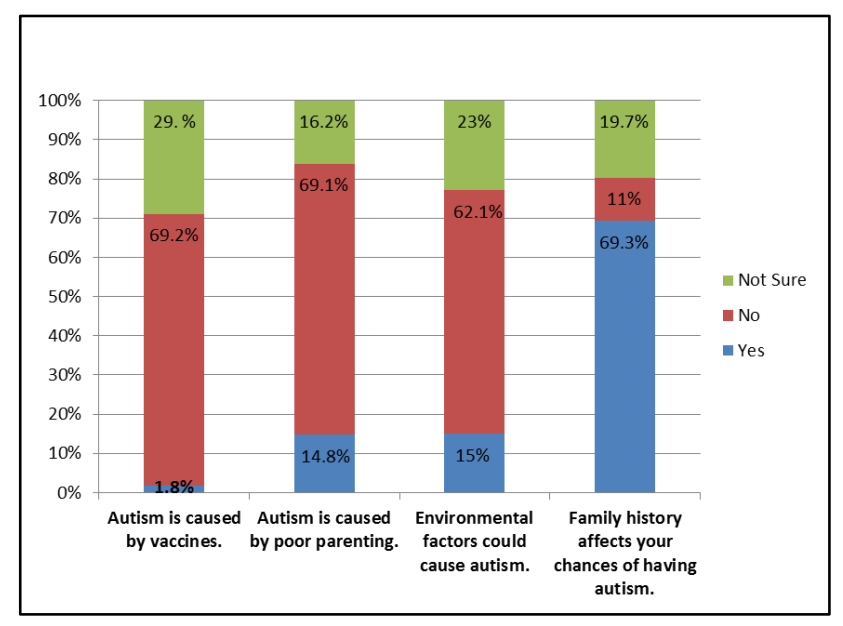

Figure 6: Responses of university students to suggested causes of autism.

\section{DISCUSSION}

Recent years have witnessed a progressive rise in ASD diagnosis that is most probably attributed to the increased case reporting as a result of increased awareness of both heath care professionals and the public. Also the availability of accurate diagnostic criteria greatly impacted the diagnosis of more cases. Such an increased prevalence is clearly shown in the rise shown between the years 1997 and 2013 from 1:500 to 1:50. ${ }^{4-6}$ Diagnosis of ASD is based on behavioural observations and reports from parents, caregivers, and professionals. Currently there are no reliable biological or neurological indicators. ${ }^{9}$ This indicates that parents, relatives and the public in general must have a reasonable level of awareness to report cases that may undergo undiagnosed and also to know how to deal responsibly with identified cases of autistic children.

In the present study the majority $(65 \%)$ of participants agreed that autism is a neuro-developmental disorder with strong genetic basis while slightly higher $(69 \%)$ number of respondents believed that family history and environmental factors increase chances of developing autism but disagreed to the statements that vaccination and poor parenting are causes of autism. This result is probably due to the efforts made by the health authorities in UAE to increase public awareness of concepts of autism and the impact of mass media in this respect. However, as such our results which may be considered reasonable are less than the $80 \%$ and $100 \%$ reported for Northern Ireland, and France respectively.,10 The majority of respondents believed that family history increases the risk of developing child autism. However, similarly high percentage of participants disagreed with the statements that poor parenting, vaccination and environmental factors are causes of autism. Also more than $50 \%$ of the respondent students perceived that autistic children are not necessarily intellectually disabled. Increased awareness and understanding of childhood autism would certainly improve the views of the public towards the sufferers of this disorder and their abilities. It has been reported that autistic individuals can develop distinctive skills in specific areas. ${ }^{11}$ Furthermore, a large number of students agreed. That early identification improves outcomes for autistic children. In addition, more than half the participants agreed that autism is a lifelong disorder with the delay in early communication being an early sign and children can outgrow the disorder. A study that approached parents of autistic children reported that parents believe that autism was a temporary condition and that with time the children will overgrow it. Also the parents overestimated the cognitive abilities of children with autism. ${ }^{12}$

In general results of this preliminary study indicate that university student's knowledge and perception of autism is good. This is most likely due to the efforts of health authorities as well as mass media to enhance public awareness of the disorder and also because of ease in gaining knowledge through the internet. Another reason may be the increased reporting of cases which led to updated high levels of prevalence of the disorder among residents of the country. ${ }^{13}$

The limitations of this study were the inclusion of only small number of participants having a relative child with autism. No attempts were made to study the influence of gender, study program or level of study on responses of students. Also the study did not assess the knowledge of 
and attitude towards autism in medical and pharmacy students in UAE as work on this is in progress.

\section{CONCLUSION}

This novel preliminary study demonstrated a good knowledge and perception of university students in the United Arab Emirates on childhood autism. The government's efforts in fostering autistic children, taking care of their health and education and supporting parents are enormous. More efforts to further enhance the understanding of autism among all members of the community are needed.

\section{ACKNOWLEDGMENTS}

The authors are greatly indebted to all the students who willingly participated in the study.

Funding: No funding sources Conflict of interest: None declared

Ethical approval: The study was approved by the Institutional Ethics Committee

\section{REFERENCES}

1. American Psychiatric Association. Diagnostic and statistical manual of mental disorders. Washington, DC; $1994 . \quad$ Available at http://www.psychiatryonline.com/DSMPDF/dsmiv.pdf. Accessed on 17 May 2016.

2. Igwe MN, Bakare MO, Agomoh AO, Onyeama GM, Okonkwo KO. Factors influencing knowledge about childhood autism among final year under graduates medical, nursing and psychology students of University of Nigeria, Enuga. Italian $\mathrm{J}$ Pediatr. 2010;36:44.

3. Rahbar MH, Ibrahim K, Assassi P. Knowledge and attitude of general practitioner regarding autism in Karachi, Pakistan. J Autism Developmental Disorders. 2011;41:465-74.

4. Williams, JG, Higgins JPT, Brayne CEG. Systematic review of prevalence studies of autism spectrum disorders. Archives of Disease in Childhood. 2006;91:8-15.

5. Elsabbagh M, Divan G, Koh YJ, Kim YS, Kauchali S, Marci'n C, et al. Global prevalence of autism and other pervasive developmental disorders. Autism Research. 2012;5:160-79.

6. Centres for Disease Control and Prevention (CDC), 2013. Available http://www.cdc.gov/nchs/data/hus/hus13.pdf. Accessed on 17 May 2016.

7. Dillenburger K, Jordan JA, McKerr L, Devine P, Keenan M. Awareness and knowledge of autism and autism interventions: A general population survey. Research in Autism Spectrum Disorders. 2013;7:1558-67.

8. National Autistic Society. Think differently - act positively: public perceptions of autism. London: National Autistic Society, 2007.

9. Matson JL, Wilkins J, Gonza'lez M. Early identification and diagnosis in autism spectrum disorders in young children and infants: how early is too early? Research in Autism Spectrum Disorders. 2008;2:75-84.

10. Durand-Zaleski I, Scott J, Rouillon F, Leboyer M. A first national survey of knowledge, attitudes and behaviours towards schizophrenia, bipolar disorders and autism in France. BMC Psychiatry. 2012;12:128.

11. Martin DN. The ever-changing social perception of autism spectrum disorders in the United States. Project completed in partial fulfillment for graduation from the Honors College of East Carolina University, 2013. Available http://libres.uncg.edu/ir/listing.aspx?id=14691.

12. Stone WL, Rosenbaum JL. A comparison of teachers and parents views of autism. Journal of Autism and Developmental Disorders. 1988;8:403-14.

13. Rai BS, Many UAE residents are still 'clueless' about autism. Available http://www.emirates247.com/lifestyle/many-uaeresidents-are-still-clueless-about-autism-2011.452669. Accessed on 17 May 2016.

Cite this article as: Sharif SI, Bughaigis LMT, Salah M, Kariem N, Mohamed A. Childhood autism: knowledge and perception among university students in United Arab Emirates. Int J Basic Clin Pharmacol 2016;5:1499-502. 